MUSEUS 


\section{La hora del museo: La Sala Uriburu del Museo Histórico y Colonial de la Provincia de Buenos Aires (Luján, 1932)'}

\begin{abstract}
María Élida Blasco ${ }^{2}$
RESUMEN: El artículo analiza el proceso de creación de la Sala Uriburu del Museo Histórico y Colonial de la Provincia de Buenos Aires instalado en la ciudad de Luján y abierto al público en 1923. La sala fue inaugurada el 4 de septiembre de 1932 y estaba destinada a honrar la memoria del líder de la "Revolución" del 6 de septiembre de 1930. El objetivo es dar cuenta de los múltiples factores que incidieron en su instalación considerando que ella no puede explicarse solamente a través de la relación directa entre coyuntura política, atmósfera nacionalista y la necesidad de crear un mito para perpetuar su memoria. Proponemos entonces explorar las prácticas y dispositivos colectivos indispensables en el proceso de creación de evidencias materiales para sustentar la visualización de un relato histórico.

PALABRAS CLAVES: Museo Histórico y Colonial. Década de 1930. Sala Uriburu. Luján.
\end{abstract}

RESUMO: $O$ artigo analisa o processo de instalação da Sala Uriburu, do Museu Histórico e Colonial da Província de Buenos Aires, fundado na cidade de Luján e aberto ao público em 1923. A sala foi inaugurada em 4 de setembro de 1932, e destinava-se a "honrar a memória" do líder da "Revolução" de 6 de setembro de 1930, poucos meses depois de sua morte. $\bigcirc$ objetivo é dar conta dos múltiplos fatores que incidiram na instalação, considerando que ela não pode ser explicada somente através da relação direta entre conjuntura política, atmosfera nacionalista e a necessidade de criar um mito para perpetuar sua memória. Propomos, então, explorar as práticas e dispositivos coletivos indispensáveis no processo de criação de evidências materiais para sustentar a visualização de um relato histórico.

PALAVRAS-ChAVE: Museu Histórico e Colonial. Década de 1930. Sala Uriburu. Luján

ABSTRACT: This article analyzes the installation of Uriburu's Hall at the Museo Histórico y Colonial de la Provincia de Buenos Aires, institution established in Luján in 1923. This hall was opened to the public in September 1932, to celebrate the name and memory of the hero

\begin{abstract}
1. Este trabajo forma parte de la investigación realizada para mi tesis doctoral referente a la formación del Museo Histórico y Colonial de la Provincia de Buenos Aires entre 1918 y 1938 , dirigida por la Dra. Irina Podgorny y defendida en marzo del 2010 Agradezco a ella el trabajo de supervisión y corrección de este escrito. También los comentarios de Raúl Fradkin y las sugerencias y recomendaciones de los dos evaluadores anónimos que leyeron el artículo.

2.Doctora en Historia egresada de la Facultad de Filosofía y Letras de la Universidad de Buenos Aires (Argentina). Becaria posdoctoral del Conicet-Archivo Histórico del Museo de La Plata. E-mail: $<$ <liblasco@yahoo.com.ar>.
\end{abstract}


3. El 6 de septiembre de 1930 , un golpe militar comandado por los grupos conservadores - alejados del control del Estado debido a la aplicación de la ley de sufragio universal conocida como Ley Sáenz Peña - y dirigido por el entonces oficial retirado José Félix Uriburu derrocó al presidente constitucional radical Hipólito Yrigoyen. Fue el primer golpe militar de la Argentina contemporánea. Estaba destinado a derrocar al Yrigoyenismo, subsanar lo que llamaban la "falta de cultura cívica popular" y recuperar el control del Estado: se produjo con importante apoyo de sectores civiles, por lo tanto en muchos casos es designado también como "movimiento cívico-militar de 1930". Uriburu asumió como Presidente Provisional y retuvo el poder hasta el 8 de noviembre de 1931 , cuando el general Agustín P. Justo fue elegido presidente en elecciones abiertas.

4. Para el caso de Brasil cabe mencionar a modo de ejemplo, las producciones de Ulpiano T. Bezerra de Meneses, Ana Cláudia Fonseca Brefe, Lorelay Kury y el conjunto de investigaciones publicadas en Anais do Museu Paulista y Revista Brasileira de Museus e Museologia.

5. Para detalles, véase Fernando Devoto (2002); Tulio Halperin Donghi (1999; 2003; 2004); Maria Dolores Béjar (2005); Sandra McGee Deutsch (2003); Luis Alberto Romero (1994; 1999; 2003);y Loris Zanatta (1996). of the Revolution of 1930. Far from proposing a direct relationship between politics and museum displays, this article wants to display the several elements that colluded in the creation of this hall.

KEYWORDS: Historic and Colonial Museum. 1930s. Uriburu's Hall. Luján.

Hacia 1930 el Museo Histórico y Colonial de la Provincia de Buenos Aires - instalado en la ciudad de Luján y dirigido desde 1923 por el historiador y publicista Enrique Udaondo - se había estructurado en treinta salas que proponían un recorrido circular: se iniciaba con referencias temporales a los tiempos de la colonia - la sala de los prisioneros, la celda, la cárcel y la sala del Cabildo - y finalizaba con la exposición de objetos referidos a las Invasiones Inglesas en Buenos Aires de 1806 y 1807 . En el recorrido, el visitante podía admirar, entre otras, las salas dedicadas: a Juan Manuel de Rosas - gobernador de la Provincia de Buenos Aires (1829-1832 y 1835-1852); a las "modas porteñas"; a los gobernadores provinciales; a los "transportes, al indio, al gaucho"; al escritor Ricardo Güiraldes; y a la Guerra del Paraguay. Mientras el Museo Histórico Nacional radicado en la ciudad de Buenos Aires se abocaba a la exhibición de "las reliquias capitales" de la vida política y militar de la Argentina, el Museo de Luján estaba orientado con un criterio que su director definía como "moderno": éste despliegue expositivo interpelaba a la emotividad y a los sentidos del público, utilizando maniquíes de cera con pelucas, adornos y vestimenta, y animales embalsamados que, supuestamente, otorgaban realismo a los escenarios que reconstruían la vida cotidiana de "antaño". En 1932 se sumaron dos nuevos salones: el Pabellón de la Capilla y la sala General Uriburu. El primero, se destinaba a albergar los objetos de arte religioso. La Sala Uriburu, en cambio, a "honrar la memoria" del líder de la "Revolución" del 6 de septiembre de 19303, a escasos dos meses de su muerte.

El presente artículo se propone analizar el proceso de montaje de la sala Uriburu para dar cuenta de la multiplicidad de factores que incidieron en su instalación considerando la escasa atención prestada por los historiadores argentinos al surgimiento y desarrollo de los museos históricos. Aunque en Brasil el panorama despliega mayor riqueza, en la Argentina los estudios se han reducido al Museo Histórico Nacional, concebido, sin mayores elementos, como escenario para la celebración y la construcción de la identidad nacional a fines del siglo XIX4 . Por otro lado, son muchas las investigaciones que desde la historia política han analizado el golpe de estado que en septiembre de 1930 derrocó al presidente radical Hipólito Yrigoyen, las medidas posteriores adoptadas por el gobierno de José Félix Uriburu y su relación política e ideológica con los grupos conservadores y los movimientos nacionalistas de la Argentina ${ }^{5}$. También la historiografía se ha ocupado de las modulaciones sufridas por la historia y los usos que en esos años hicieron los historiadores del relato de los acontecimientos del 6 de septiembre. En este contexto debemos mencionar el detallado trabajo centrado específicamente en la construcción política y cultural del "mito" del General Uriburu que incluye al Museo de Luján como uno de los "lugares de la memoria uriburista"b y la reutilización del mito en los años posteriores por parte de los diri- 
gentes políticos de la Provincia de Buenos Aires ${ }^{7}$. $\bigcirc$ de manera más general, las últimas investigaciones sobre historia de la historiografía que analizan desde una perspectiva temporal y flexible los rasgos, problemas y elementos identificatorios de una tradición historiográfica denominada genéricamente como liberal, "oficial" o "académica" - que en los años que analizamos estaría representada por los historiadores nucleados en la Nueva Escuela Histórica -, frente a otra que se suele etiquetar bajo el rótulo de "revisionista" enfatizando sus posturas nacionalistas y la reivindicación de los caudillos, especialmente - aunque no solo - de la figura de Juan Manuel de Rosas. En este marco, luego del golpe del 6 de septiembre, gran parte de los historiadores vinculados a estas tradiciones se esforzaron por abonar, rechazar o matizar las interpretaciones que presentaban a Yrigoyen o a Uriburu como un nuevo Rosas y aquellas que reubicaban el 6 de septiembre como uno de los acontecimientos más "felices" o "nefastos" dentro del período fundacional de la historia argentina, después de Mayo de 1810 o de la batalla de Caseros que en 1853 llevó a Rosas al exilio ${ }^{\text {. }}$

Estas páginas proponen complejizar el análisis considerando que la instalación de lugares y relatos dedicados a generar una determinada memoria asociada en este caso al "líder de septiembre" no pueden explicarse solamente a través de la relación directa y esquemática entre coyuntura política e historiográfica, atmósfera nacionalista y la necesidad de crear un mito para perpetuar la memoria. Si bien sostenemos que esta relación existió y se hizo palpable a través de la movilización de recursos y las relaciones personales entre el director del Museo, las agrupaciones nacionalistas, los miembros del ejército y la elite gubernamental, esta investigación propone incorporar nuevas dimensiones: nos referimos a las prácticas y dispositivos colectivos indispensables en el proceso de creación de evidencias materiales para sustentar la visualización de un relato histórico determinado?. La exploración de esta infraestructura material mucho menos vinculada a las intencionalidades e intereses políticos - pero sobre la que se sustentó la concreción del proyecto - contribuye a analizar la complejidad de un hecho que se materializó puertas adentro del museo pero que, en un contexto político particular, alcanzó una trascendencia mayor a la imaginada por sus propios ideólogos.

En primer lugar exploramos las actividades del museo durante el gobierno de Uriburu - entre el 6 de septiembre de 1930 y el 20 de febrero de 1932 modeladas por la relación entablada entre Udaondo, Uriburu y algunos referentes de la elite gubernamental vinculados al nacionalismo católico; en segundo lugar, analizamos las circunstancias que hicieron posible la concepción y concreción del proyecto de montar una nueva sala en el museo. En tercer lugar, los modos diversos a través de los cuales las prácticas previas no solo de Udaondo sino también de una nutrida red de coleccionistas, comerciantes, artistas y trabajadores ajenos muchas veces a intereses políticos concretos, fueron otorgándole entidad material y pública a la propuesta. Finalmente, nos detenemos en las controversias surgidas a raíz de la inauguración de la sala, respecto a las especificidades del rol del museo y sus vinculaciones con la política en un contexto signado por un
6. Véase Federico Finchelstein (2002).

7.Véase Andrés Bisso (2010).

8. Véase Diana Quattrocchi-Woisson (1995); y Alejandro Cattaruzza (2001). Sobre revisionismo histórico en las décadas de 1930 y 1940 , véase Alejandro Cattaruzza (2003); Fernando Devoto y Nora Pagano (2009, p. 201285).

9. Véase Irina Podgorny (2000; 2005); y aun Maria Margaret Lopes e Irina Podgorny (2008). 
10. Véase El Pueblo, Buenos Aires, 9 sept. 1930; y La Nación, Buenos Aires, 18 sept. 1930.

11. Véase El Progreso, Luján, 6 y 27 sept. 1930; Crítica, Buenos Aires, 19 y 29 sept. 1930; El Diario, Buenos Aires, 19 y 29 sept. 1930; $E l$ Mundo, Buenos Aires, 19 y 29 sept. 1930; El Pueblo, Buenos Aires, 29 sept. 1930; y Nativa, 1. oct. 1930.

12. Cf. Loris Zanatta (1996, p. 90).

13. CARTA de Rafael D. del Villar a Udaondo, 31 marzo 1931, caja 47, f. 140; Borradores de la memoria del año 1930, caja 47, f. 148-153, Fondo Udaondo de la Academia Nacional de la Historia.

\section{Ibidem.}

15. CARTA de agradecimiento de Udaondo a Uriburu, 1. oct. 1931, Copiador: cartas y notas de Udaondo (octubre 1929-abril 1933), f. 525; CARTAS de agradecimiento de Uriburu a su "Estimado amigo Udaondo", 28 oct. y 15 dic. 1932; ACTAS de donaciones Sala Uriburu, correspondencia, Archivo del Complejo Museográfico Enrique Udaondo, Luján.

16. ACTAS de donaciones de la Sala Uriburu, correspondencia, Archivo del Complejo Museográfico Enrique Udaondo, Luján.

17. El 2 de enero de 1931, Udaondo era invitado a concurrir a una entrevista en el despacho del Interventor Nacional Interino de la Provincia de Buenos Aires; cf. NOTIFICACIÓN oficial del Ministerio, Caja 47, f. 143 , Fondo Udaondo de la Academia Nacional de la Historia. mayor interés en la memoria histórica y un nuevo papel asignado a la historia y los historiadores por parte de los administradores del aparato estatal.

El Museo de Luján durante el gobierno de Uriburu

A pocos días de la asunción de Uriburu una nueva camada de interventores y comisionados comenzaron a instalarse en los cargos ejecutivos de provincias, municipios y diversas reparticiones públicas. Muchos funcionarios nombrados bajo la administración radical fueron removidos de sus cargos, sin embargo el Interventor de la Provincia de Buenos Aires rechazó la renuncia presentada por Udaondo y "teniendo en cuenta los servicios prestados al frente del museo" lo confirmó al frente del instituto ${ }^{10}$.

Aunque la situación políitica obligó a postergar el acto de inauguración del monumento ecuestre a Manuel Belgrano que el director del Museo de Luján había previsto para el 7 de septiembre de 1930, hacia el 20 de ese mes, en Luján se exhibía el primer maniquí del General San Martín, un muñeco de cera de tamaño natural confeccionado con la colaboración de la Administración General del Ejército. También se inauguró una reconstrucción de la sala de acuerdos en donde sesionó el Cabildo de la Villa de Luján desde 1756, acompañada de maniquíes de cera que representaban a los cabildantes vestidos con la indumentaria característica de fines del siglo XVIII' ${ }^{1}$.

Además el museo participó activamente de los festejos del 6 de octubre para conmemorar el Tercer Centenario del Milagro de la Virgen de Luján, una verdadera demostración de fuerza de la militancia católica que contó con la presencia de las autoridades de la Argentina, Paraguay y Uruguay, y donde se exaltó la labor del Ejército como "custodio del catolicismo"12.

Efectivamente, las relaciones entre Udaondo y las nuevas autoridades políticas se intensificaron a partir del golpe: el director del museo mantenía contactos informales con el Ministro de Relaciones Exteriores y ellos eran utilizados para obtener beneficios para el museo: el 22 de diciembre de 1930, por ejemplo, se sabía "extraoficialmente que el gobierno ha dispuesto que las carrozas históricas sean cedidas para su custodia y exhibición al Museo Histórico"13. Se trataba de "dos hermosas carrozas que pertenecieron a los Presidentes de la Nación y los gobernadores de la Provincia"14. Pero Uriburu también colaboraba con el museo legando alguno de sus objetos personales: en septiembre de 1931 donó un retrato al óleo de su "ilustre antepasado" el General Antonio Alvarez de Arenales, que el director destinó a la sala Independencia ${ }^{15}$. Además, el 25 de octubre, el director del museo organizó un "gran desfile retrospectivo de rodados"16 del cual envió fotografías y folletos institucionales al presidente del Gobierno Provisional.

También el Gobierno de la Provincia había cedido al museo "el artístico tintero de plata"17 que había pertenecido a Bernardino Rivadavia. En este contexto, el director elevó las memorias oficiales destacando el apoyo brindado 
por las autoridades gubernamentales desde la "Revolución" de septiembre aunque no dejaba de mencionar las cuestiones pendientes:

Desde hace años la dirección del Museo viene bregando por el ensanche y tratando de obtener los terrenos linderos al mismo, este año en el mes de septiembre, pudo tomar posesión del lote de la esquina, pero aún quedan otros dos que están afectados por una ley y que solo se espera el pago cuyo impuesto total es de 65.000 pesos moneda nacional ${ }^{18}$

y finalizaba con la esperanza de que los reclamos fueran atendidos por alguno de sus allegados vinculados a la función pública.

La Sala Uriburu

En un intento de brindar continuidad a la recomposición de fuerzas políticas surgidas desde el 6 de septiembre, en noviembre de 1931 se llevaron a cabo elecciones nacionales y la coalición de fuerzas políticas nacionalistas afines a Uriburu - de posiciones de derecha más corporativas y extremas - terminó aceptando como "el mal menor" la candidatura de Agustín P. Justo, un general del ejército que había sido Ministro de Guerra del presidente radical Marcelo T. de Alvear y de un perfil ideológico conservador pero moderado. El 20 de febrero de 1932 cuando Justo asumió la Presidencia de la Nación, los conflictos internos respecto al sistema de alianzas entre las diferentes facciones del poder estaba ya dirimido. Sin embargo, la necesidad de reivindicar los objetivos políticos corporativos de la "Revolución" del 6 de septiembre continuaba latente entre los miembros de las agrupaciones nacionalistas.

En este contexto, el 29 de abril de 1932 se produjo la muerte de Uriburu en París, ciudad a la que el ex presidente había viajado para tratar su enfermedad. Dos meses después un allegado de Uriburu, Carlos Rivero, informó a Udaondo que el Teniente Coronel Juan Bautista Molina - ex secretario general de la presidencia de Uriburu - había adquirido a nombre de ambos "la cama y la mesa de luz que pertenecieron a la habitación de la clínica que ocupó y donde falleció el General Uriburu en París" 19. La intención de Molina era ofrecerlo como recuerdo a la familia pero Rivero consultaba a Udaondo "sobre la posibilidad de donarlo al Museo de Luján con el objeto de iniciar con ello un lugar recordatorio de nuestro bien querido general"20. Dada las simpatías de Udaondo con el "líder" del 6 de septiembre, la respuesta fue afirmativa y el 2 de julio Molina y Rivero remitían los muebles acompañados de los certificados correspondientes que los autenticaban "con el objetivo de dar comienzo a la iniciativa"21. También habían gestionado ante Aurelia Madero de Uriburu, viuda del general, la donación de uniformes y otros efectos personales. El 18 de julio se firmó el acta de donación de estos objetos (armas antiguas, pergaminos, diplomas, fotografías y utensilios personales) y hecha pública la iniciativa comenzaron a llegar donaciones para la nueva sala que Udaondo tenía previsto inaugurar el 4 de septiembre, en el marco
18. Ver nota 13 .

19.ACTA de donaciones Sala Uriburu, f. 13 C.

20. Ibidem.

21. ACTA de donaciones Sala Uriburu, f. 14, 14 bis, 15; PAPELES Sala Uriburu, f. 5-8, Archivo del Complejo Museográfico Enrique Udaondo, Luján. 
22. PAPELES Sala Uriburu, $\mathrm{f}$. 34-35, Archivo del Complejo Museográfico Enrique Udaondo, Luján.

23. Véase Bandera Argentina, Buenos Aires, sept. 1930

24. BORRADORES de la programación del acto, caja 47 , f. 226-229, Fondo Udaondo de la Academia Nacional de la Historia.

25. EN EL MUSEO Histórico de Luján, El Oeste, Buenos Aires, oct. 1932. Respecto a la jornada en Luján, véase también INICIOSE la conmemoración del aniversario del 6 de septiembre, en La Razón, Buenos Aires, 4 sept. 1932; QUEREMOS una Argentina gobernada por argentinos, en La Fronda, Buenos Aires, 5 sept. 1932

26. Véase $E l$ Oeste, Buenos Aires, oct. 1932.

27. Ibidem.

28. Ibidem

29. Ibidem. de las celebraciones del aniversario del "golpe", pero a menos de tres meses de ocurrida la muerte del ya considerado "prócer".

El 12 de agosto la noticia se hizo pública a través del diario nacionalista Bandera Argentina. El 19 del mismo mes, el secretario de la gobernación de la Provincia de Buenos Aires envió un telegrama poniendo sobre aviso a Udaondo de que el Gobernador concurriría al acto de inauguración de la sala 22 y el 30 se publicó el decreto oficial. En el curso de la semana, la información se difundió en los principales periódicos del ámbito porteño y con especial énfasis en aquellos medios gráficos nacionalistas convencidos de que el 6 de septiembre de 1930 "el pueblo y el ejército habían devuelto a la República la dignidad ultrajada"23. Con estas palabras Bandera Argentina incentivaba a "todos los argentinos" a concurrir a los actos que comenzarían el domingo 4 de septiembre a las 15 horas en Luján ${ }^{24}$.

Las actividades se iniciaron por la mañana con disparos de bombas y continuaron hasta el mediodía con una audición musical aguardando la llegada de la comitiva oficial para las horas de la tarde ${ }^{25}$. Según las crónicas periodísticas, el tren especial llegó con más de 1400 personas "que entonaban canciones patrióticas vivando a Uriburu y a la Revolución" 26 . En el palco levantado frente al museo aguardaba Udaondo acompañado por la familia Uriburu y los integrantes de la Comisión de Homenaje. Luego de entonar el Himno Nacional tomó la palabra el Intendente, el presidente de la Comisión de Homenaje, y el representante político de la provincia de Buenos Aires quienes exaltaron la iniciativa de Udaondo destinada a quienes "hartos ya de un disolvente cosmopolitismo que todo lo mancha y lo conmueve, sentimos la sublime inquietud de la Patria"27. En nombre del gobernador éste último alertó:

Vive el mundo horas confusas que fomentan el desarrollo de sentimentalismos perniciosos. Una onda negra como el odio pasa por la frente de los hombres y les dice al oído una palabra siniestra. Y esos hombres para quienes es a veces duro el camino de la vida, los que convierten la utopía en absurdo y trasforman el absurdo en crimen, los que tienen rebosante el corazón de rencores, oyen la voz siniestra y marchan en forma de columna ${ }^{28}$.

Y ante las posibles dudas generadas en la audiencia arriesgaba nuevas pistas para reconocer al enemigo:

Son muchos y no saben lo que quieren. Han andado y no saben dónde van. Han empezado a deshacer y no saben construir. Han agraviado y no temen a la reacción. Pero no ha de explicar nadie por qué en nombre de los males que sufrieron en Europa, se atenta contra el orden social de nuestro país; por qué las razas sometidas por siglos a la férrea disciplina zarista, ejercitan aquí la libertad en forma de licencia, de desorden y de delito; por qué algunos extranjeros a quienes acogemos como hermanos, emprenden la obra oscura de la deslealtad; por qué, en una palabra, al amparo del preámbulo constitucional que invita a los hombres de buena voluntad, pasa la muchedumbre rencorosa y disolvente cuya amargura se puede compartir - porque todos somos partícipes en el dolor universal - pero de cuyos agravios nadie tiene el derecho de hacernos destinatarios ${ }^{29}$. 
Pero al final del discurso se hacía necesario explicitar el peligro: ni "los trapos rojos de la anarquía, ni los cantos comunistas ni las organizaciones del Soviet", podían tener cabida en el "suelo de la patria", finalizaba.

A continuación, el director del museo respondió públicamente a las críticas recibidas respecto a la temprana consagración histórica de Uriburu. Según su opinión, "la apoteosis que le tributó el pueblo de Buenos Aires" ilustraba el modo en que "se ha pronunciado la conciencia nacional" 30 respecto a su actuación política. Y apelaba a la historia para legitimarla:

Sus contemporáneos podrán discutir su actuación pública como en su hora lo hicieron con San Martín, con Rivadavia y con Mitre, pero nadie le negará su abnegación al rehusar perpetuarse en el poder no obstante contar con la opinión pública y el Ejército: convoca a elecciones para entregar el mando supremo en plena paz ${ }^{31}$.

Además, comparaba la actuación pública de Uriburu con la del General José María Paz "tan discutida en su hora", estableciendo como analogía el haberse distinguido como "conductores prestigiosos del ejército", ese "glorioso" ejército "tan combatido por los elementos anárquicos":

Es justo señores que en esta hora de confusión que vive el mundo, los argentinos reaccionemos contra los que aspiran a imponer doctrinas exóticas a nuestra nacionalidad, pretendiendo destruir todas nuestras más sagradas tradiciones. Señores: agradezco la presencia del señor gobernador de la provincia que ha querido solemnizar este acto y declaro inaugurada la sala General Uriburu, el ilustre ciudadano muerto lejos de la patria pronunciando palabras de perdón, con la valentía de un militar y la serenidad de un justo, acompañado de las bendiciones del cielo, rodeado del afecto de su familia ejemplar, de sus fieles, camaradas y del cariño de todo el pueblo consciente de la República32.

Los objetos de la Sala Uriburu

El montaje de la nueva sala demandaba apoyo político para la movilización de recursos y solventar los gastos, pero también una amplia diversidad de mecanismos que sustentaran el proceso de transformación de objetos en "evidencias" e hicieran posible la creación de "objetos históricos". Recordemos que, por decisión de sus ideólogos, la sala Uriburu contenía una "colección" de objetos creada deliberadamente para exaltar los valores de un hombre considerado "líder" de un acontecimiento político reciente y las piezas materiales serían expuestas como "evidencias" capaces de sustentar ese relato de la historia. Por lo tanto, si bien la tarea de recolección y acopio de objetos estaba sustentada en las prácticas previas ya conocidas por el director - rastreo de piezas consideradas significativas, solicitud de ellas a sus antiguos propietarios y recepción de donaciones -, por la cercanía temporal de los hechos y la urgencia de la inauguración, debió apelar con mayor amplitud a una variedad de colaboradores para "fabricar" objetos. 
33. ACTAS de donaciones Sala Uriburu, f. 53 M,Archivo del Complejo Museográfico Enrique Udaondo, Luján.

34. Ibidem.

35. Idem, f. 4 B.

36. Idem,f. 16, 65-67 y $71 \mathrm{MG}$.
Además de la cama que había utilizado el difunto y las armas y utensilios personales donados por la viuda, Udaondo revisó el inventario de objetos ya ingresados al museo para trasladar a la nueva sala aquellos que pudieran vincularse con los sucesos a evocar: en este contexto trasladó algunas de las piezas que en 1931 había donado el ex presidente José Evaristo Uriburu - tío de José Félix - para la sala Independencia. También el 13 de enero de ese año la presidenta de la Comisión de Damas Pro Homenaje al Ejército había entregado un ejemplar de "la Cruz de Fierro, similar a las que se impusieron en el Colegio Militar el día 23 de diciembre pasado a los jefes y oficiales del Ejército Argentino que más valiente y destacada actuación tuvieron en los sucesos memorables del 6 de septiembre de 1930"33. Se trataba de una condecoración que "la mujer argentina" había entregado a los miembros del ejército en señal de gratitud por su "valentía" en el "movimiento cívico". En el momento de la donación, Udaondo había destinado la pieza a otra sala pero ante la inminente inauguración, la trasladó a la Uriburu ${ }^{34}$.

Como vemos, si bien en 1931 se desconocía la intención de formar una sala destinada a Uriburu, ya estaba instalada en los protagonistas y simpatizantes de las jornadas de septiembre, la práctica de resguardar objetos vinculados a hechos que, aunque cercanos, eran concebidos como "históricos". Esto explicaba en parte la intencionalidad de un allegado a Udaondo que el 26 de septiembre de 1931 donaba los "tesoros" obtenidos por su sobrino que, por haber sido cadete en el momento de la revolución, tenía

varias balas de las que se tiraron al Congreso en el conocido episodio y fueron sacadas [...] de las paredes en donde estaban incrustadas. Como esas balas tienen la virtud histórica de haber sido dirigidas por el propio ejército Nacional contra el Palacio de las Leyes por creerse corrompido, inocuo y nocivo para la nación cobran por lo tanto valor histórico y se los ofrecemos ${ }^{35}$.

Esta carta forma parte de las actas de donaciones de la Sala Uriburu, por lo que inferimos que las balas fueron expuestas en este ámbito. Sobre la base de estas prácticas compartidas al menos por los adherentes a Uriburu, Udaondo continuó el trabajo de acopio de objetos. Puesto en conocimiento de la inauguración de la nueva sala el 25 de julio de 1932, Fortunato José Imundo, por ejemplo, entregó un retrato de 1910 y una lista de fotografías de Uriburu tomadas por el mismo donante, y David Uriburu le envió cuatro retratos que fueron colocados en marcos apropiados ${ }^{36}$. Pero lo inminente de la inauguración hacía necesaria la circulación de información sobre el paradero de otras piezas, además de retratos y fotos. Por ese motivo, el 28 de agosto de 1932 Hernán Maschwitz ponía en conocimiento a Udaondo de que Juan Carlos Amadeo tenía en su poder una lanza que había sido de Uriburu y que este le había obsequiado hacía muchos años. El problema era que se había extraviado la carta que demostraba su autenticidad y por ese motivo, decía Maschwitz, Amadeo no quería cederla al museo: "yo le he dicho - proseguía - que tratándose de un entendido y coleccionista como él, amigo de la verdad histórica por demás, nadie podrá dudar de su palabra si al hacer la donación explica en una carta firmada por qué es que la tiene en su 
poder" 37 . Maschwitz intentaba gestionar la donación por eso había hablado con Amadeo y ahora lo hacía con el director del museo.

Como vimos también en los ejemplos sobre las balas, la cruz de fierro y ahora la lanza, la autenticidad de los "objetos históricos" estaba basada en el relato que pudiera aportar una persona considerada "autoridad" competente en la materia. Sin embargo, tampoco este mecanismo era indispensable para que una pieza pasara a formar parte de la "colección Uriburu", mucho menos cuando los elementos eran provistos por el circuito comercial como lo eran los cuadros ofertados por los artistas. Un ejemplo de ello lo constituye el ofrecimiento realizado el 2 de septiembre de 1932 por el pintor italiano Humberto Cacciarelli quien intentaba vender un cuadro al óleo ejecutado en base a un croquis que él mismo había tomado el día del "movimiento popular"38. Adjunta a una carta escrita en italiano, le enviaba una cartulina reproduciendo el cuadro de su autoría La bandera del Parlamento en la casa de gobierno de Buenos Aires, el 6 de septiembre de 1930. También le informaba que el precio era de 2000 pesos. El 11 de septiembre, luego de la inauguración de la sala, Udaondo le comunicó que por razones económicas, no estaba interesado en su adquisición, pero el pintor continuó insistente su ofrecimiento. El 24 de octubre le envió la siguiente carta:

En mi última le dije de noticias desagradables que he recibido de Roma el otro día y que me obligan todavía a hacer sacrificio.

Hubiera podido sacrificar el cuadro grande que Ud. conoce ("La visita del Cardenal") pero prefiero recibir para Pascua, la llega a Roma de un señor Plaut de New York que todos los años me compra un cuadro [...] Este señor, como también todos los de Norteamérica me ha pagado por este cuadro un precio que aquí sería absurdo de pensar.

Pero Pascua es lejana y yo tengo que resolver "mi crisis" en pocos días porque me obligan compromisos serios.

Por estos motivos es por qué cedería el cuadro del 6 de septiembre a un precio irrisorio, además uniría unas 1200 estampas como la adjunta y 1000 postales como la que Ud. conoce.

El cuadro cuya tela mide 80 por 120 con la corniz externamente de 105 por 145 es una buena corniz que me ha costado 80 pesos, que unida a los gastos de tela, colores, estudios, estampas y pasteles resúltame una discreta suma. Solo pido por el cuadro 800 pesos y lo cedería también en algo menos [...]. En estos momentos de tristeza quemaría todas mis obras y como bohemio y filósofo no pensaría más; pero tengo personas queridas en Roma que viven de mi trabajo y con mi pensamiento en el corazón ${ }^{39}$.

La lacrimógena carta del pintor refleja al menos dos aspectos relevantes: por un lado, la participación de algunos artistas en el circuito de fabricación de objetos, un hecho que si bien ha sido señalado para los museos argentinos, merecería una reflexión más detenida a la hora de analizar las piezas expuestas en los museos denominados "históricos". Por otro lado, también advierte sobre la distancia entre lo expuesto y los objetivos primigenios del director de la institución. En este caso, se trataba de todas aquellas piezas que llegaban a manos del director a través de múltiples y diversos mecanismos: compra personal con dinero privado del director, intercambio, donación etc. $Y$ dentro de estos mecanismos,
37. Idem, f. $52 \mathrm{C}$.

38. Idem, f. 17-25 C.

39. CARTA de Humberto Cacciarelli, 24 sept. 1932; ACTAS de donaciones Sala Uriburu, f. 17-25 C, Archivo del Complejo Museográfico Enrique Udaondo, Luján. 
40.ACTAS de donaciones Sala Uriburu, f. 26 C.

41. NOTA de Humberto Cacciarelli, 1932; Actas de donaciones Sala Uriburu, , f. 17-25 C, Archivo del Complejo Museográfico Enrique Udaondo, Luján; destacado en el original.

42.ACTAS de donaciones Sala Uriburu,f. 17-25 C, Archivo del Complejo Museográfico Enrique Udaondo, Luján. también era recurrente el ofrecimiento de cuadros y pinturas que intentaban ser vendidos al museo como producto del trabajo del artista o, como en este caso, para hacer frente a una acuciante situación económica. En este contexto, también podemos mencionar el caso de un señor que el 17 de octubre de 1932 ofreció un cuadro de Uriburu a través de la siguiente carta:

En estas épocas de angustias económicas y morales, no sabemos a que medios recurrir para poder vivir. ¿̇No es acaso humano Dr. Udaondo, revivir a quien de antemano sabemos un caballero?. Por eso hice exclusivamente para Ud. este dibujo a lápiz del General Uriburu. ¿Vale algo?. No señor. No voy a venderlo; le obsequio con él y me consideraré bien pagado con que me tienda una pequeña ayuda. Si Ud. me lo permite pasaré a molestarlo maña$\mathrm{na}^{40}$.

Las ofertas eran variadas y algunas parecían cobrar interés para Udaondo. En una nota enviada a fines de 1932, el pintor Cacciarelli lo convencía de las posibilidades económicas generadas por la venta de postales:

De las postales que Ud. conoce le dejaría también el cliché para la impresión. Dichas postales no han sido nunca vendidas en público, mientras vendidas en el Museo y con el sello de éste se podrían vender 0,10 centavos cada una y a fin de año salir millones. La estampa grande también que se vendiese a 25 o 30 centavos podrían dar un buen margen, y si se podría hacer copia a tricromía o fotocromía como esa de la Procesión Papal que Ud. conoce, podrían dar un margen tal que cubriría los gastos del cuadro y quizás obtener también buena ganancia, distribuyendo en todo el territorio ${ }^{41}$.

En realidad, lo explícito de la propuesta de Cacciarelli estaba demostrando no solo la importancia sino la vigencia y aceptación de esta lógica comercial de compra y venta de objetos, recuerdos y souvenirs como práctica asociada a los museos. Conocedor de los mecanismos utilizados mundialmente para generar trabajos y ganancias vinculadas a los museos, le sugería que la institución impusiera "su marca" para aumentar el valor de las estampas. El negocio parecía adecuado; por lo tanto el 27 de febrero de 1933 el director labró el acta de ingreso del cuadro - a la que además se habían sumado 1000 postales de cartulinas ilustradas y 1200 láminas grandes - que el pintor había vendido finalmente en 600 pesos. En el acta se informaba que

según declaración de su autor, que figura en el cuadro, fue hecha de un apunte del natural. Aparece la multitud que acompañó al General Uriburu en el momento de entrar dicho jefe a la Casa de Gobierno, rodeado por el pueblo. Es un cuadro que tiene mucho movimiento y que da la sensación del acto que representa ${ }^{42}$.

Sin embargo, la inauguración de la nueva sala había sido anunciada y había que colmarla de "reliquias". Para ello, el 27 de julio Udaondo solicitó una de las últimas innovaciones tecnológicas en materia de exhibición: una fotoescultura en bronce de Uriburu que fue donada por el Director del Instituto Foto Técnico Argentino ${ }^{43}$. Hacia 1929 el agrimensor porteño Antonio Saralegui había 
comenzado a esbozar los conceptos teóricos de la fotoescultura "un procedimiento argentino, patentado mundialmente para la construcción mecánica de esculturas tomando como base las fotografías obtenidas con nuestras cámaras fotográficas especiales"44. Tal como lo advertía la propaganda del instituto, el director del museo tenía a su disposición una amplia oferta de tamaños, materiales y precios para la construcción de la fotoescultura del líder de la revolución del 6 de septiembre:

Porcelaninas blancas, mitad del tamaño natural...\$10.

Bronces en mitad del tamaño natural, con base de mármol...\$50.

Bronces en mitad del tamaño natural, con tinteros sobre mármol onix, para escritorios...\$120.

Yesos en tamaño natural imitando bronce...\$20.

Marmolinas blancas, en tamaño natural...\$50.

Bronces en tamaño natural, sin cuerpo (cabeza y cuello) ...\$300.

Bronces en tamaño natural, con cuerpo hasta la cintura...\$500.

Bronces en una vez y media mayor que el tamaño natural, sin cuerpo (cabeza y cuello).. \$1000.

Bronces en una vez y media mayor que el tamaño natural, con cuerpo hasta la cintura, preparado para monumentos... \$150045.

La seleccionada por Udaondo era construida "en bronce con base de mármol en mitad de su tamaño natural" - por un costo de 50 - "de acuerdo a las placas tomadas en la casa de Gobierno en el mes de mayo de 1931 ". La información iba acompañada de la fotografía de la escultura terminada y de la correspondiente publicidad: "solicítelas en nuestro estudios o en las principales casas de comercio".

Como vemos, la fabricación de objetos para la exposición pública necesitaba (pero a la vez difundía) los beneficios de la innovación tecnológica y de las casas comerciales dedicadas a la oferta de nuevas mercancías y nuevos servicios. Insertos en estas redes, circulaban una amplia variedad de conocimientos, técnicas y prácticas disponibles para el montaje de las salas y la recreación o restitución de escenas: la utilización de muñecos de cera al interior del Museo de Luján, por ejemplo, iba acompañada de un mercado ya conocido en el mundo y cada vez más amplio en Buenos Aires de casas comerciales especializadas en la fabricación maniquies y en ornamentación de muñecos en base a réplicas obtenidas de reproducciones fotográficas, pinturas, bocetos o fotos originales. Apelando a ello, el 13 de agosto de 1932 Udaondo encargó un maniquí de cera reproducción de Uriburu de "cuerpo entero, cabeza y manos de cera" a la casa La France Ortega por un valor de 350 \$46.

Además, se apuró a activar el circuito comercial que garantizaba también la realización con éxito del respectivo acto oficial de inauguración. El 22 de julio de 1932 encargó 2 vitrinas en la Carpintería Italiana de Aurelio Sívori; el 5 de agosto pagó 2 colchones a la carpintería y mueblería de Mignone Hermanos y el 31 a la casa de Sebastián de Amorrortu por 32 leyendas para fotografía de Uriburu, 300 tarjetas de invitación para el acto del 4 de septiembre, 500 tarjetas con membrete del museo y 500 sobres comerciales. En septiembre encargó
43. Idem, f. 4 B, 137, 68-70 MG.

44. PROPAGANDA del Instituto Foto Técnico Argentino. Actas de donaciones Sala Uriburu, f. 69 MG, Archivo del Complejo Museográfico Enrique Udaondo, Luján.

45. Idem, f. 70 MG

46. En PAPELES Sala Uriburu, f. 26; ACTAS de donación, $\mathrm{f}$. $18,20,21,22,27,30,63 \mathrm{MG}$, Archivo del Complejo Museográfico Enrique Udaondo, Luján. 
47. FILM de septiembre, $L a$ Vanguardia, Buenos Aires, 4 sept. 1932, 7 sept. 1932, p. 1 , apud Federico Finchelstein (2002, p. 100)

48. ACTAS de donaciones de la Sala Uriburu, f. $72 \mathrm{MG} ; 51$ E; PAPELES Sala Uriburu,f. 29, Archivo del Complejo Museográfico Enrique Udaondo, Luján.

49. ACTAS de donaciones de la Sala Uriburu, f. 51 E,Archivo del Complejo Museográfico Enrique Udaondo, Luján. productos a la casa introductora de artículos navales Francisco Francioni y Cia; pagó un monto de 53,20 \$ por "3 banderas argentinas de lanilla, 3,5 m de cinta bandera argentina y el alquiler de 4 cortinados de felpa y 3 caminos" a la lonería y empresa de adornos Sucesión Segunda de Longobardi de Buenos Aires y retiró 30 kilos de yerba del almacén El Gato Negro por los cuales pagó 33 \$.

Pero dado el explícito apoyo gubernamental a la iniciativa, algunos de los productos no llegaban vía comercio: el 1. de septiembre de 1932, por ejemplo, a solo tres días de la inauguración, el dentista Humberto Curatella Manes ofreció "desinteresadamente" 4 mil postales de la mascarilla de Uriburu, reproducción de la obra de su afamado hermano, el escultor Pablo Curaletta Manes que por esos años se hallaba radicado en París. La carta informaba que dejaba a criterio del director el empleo de las postales "en la forma que crea más conveniente"; por ese motivo Udaondo las empleó para repartirlas el día de la inauguración de la sala.

Pero a pesar de estos esfuerzos para lograr el acopio de reliquias, el diario socialista La Vanguardia parecía mofarse de la pobreza de la muestra:

Un cuarto en el museo. Apariencia humilde de alcoba de sabio. Pero bagaje nada representativo de sabiduría: las botas, el sable, la cama [...]. Uriburu, el general tiene en el museo de Luján una estatua de cartón. Con botas, medallas y todo. Inmortalidad provisional ${ }^{47}$.

Para los nacionalistas en cambio, la inauguración oficial fue un éxito; una visión compartida también por el director del Museo quien luego del evento observó la velocidad con que se multiplicaban los objetos cedidos para la nueva sala: el 7 de septiembre la Óptica Mándel donaba un cuadro del "gran patricio", como así también lo hacían la mayor parte de los allegados a Udaondo, los jefes, oficiales y coroneles del ejército, miembros de agrupaciones nacionalistas, familiares y simpatizantes del general venerado ${ }^{48}$. En efecto, los cuadros retocados, óleos, fotografías diversas (originales y reproducciones) eran los objetos más ofertados. Estas láminas que hacia 1930 circulaban masivamente se transformaron en un verdadero aluvión gráfico ofrecido al director del museo. Por otro lado, además de la cama, la mesa de luz, unas pocas armas y balas, y los objetos entregados por la viuda de Uriburu, los objetos expuestos en la sala en su mayor parte eran fotos y pinturas además del busto y el maniquí de cera. Por ese motivo, el director del museo había aceptado como una verdadera "reliquia" la donación realizada por la Sra. Laura Carlés de Guerrico pocos días después de la inauguración: "la espada del General Uriburu que mi hijo César me trajera la noche del 6 de septiembre y que yo guardaba como orgulloso recuerdo de aquel día memorable" 49 .

Hacia 1934 entonces, el catálogo institucional ilustraba las vistas de la sala donde predominaban los cuadros, retratos y pergaminos de homenaje tanto de José Félix como de su padre y sus tíos que habían participado en diferentes campañas militares. Además, se exponía la "fotoescultura" del general que el 7 de marzo de 1933 Udaondo había encargado nuevamente a la casa comercial pero ahora de menor valor: se trataba de una "placa en yeso imitando bronce" 
a un "precio especial" de 75 \$ que sufragó de su propio peculio para donarlo al museo. También se exhibía una vitrina con objetos personales utilizados durante la presidencia (montura militar, pistoleras, anteojos, etc); un catre y baúl de campaña; un sable, panoplias de armas, la cama y mesa de luz que habían dado inicio a la sala; el parabrisa del automóvil en el que iba Uriburu el 6 de septiembre con una perforación de bala y también, como en otras salas, un maniquí se cera reproduciendo la figura del general con el uniforme que "había llevado el día de la Revolución" y usaba a diario siendo presidente.

La controversia: la funcionalidad política del "museo moderno"

El montaje de la Sala Uriburu suscitó controvertidas opiniones sobre todo en aquellos sectores sociales que veían con temor el avance de las ideas de los grupos vinculados a la derecha católica y nacionalista: el 31 de agosto de 1932, El Diario, órgano periodístico de inspiraciones políticas cercanas a las de la Unión Cívica Radical, publicó una nota titulada El fallo de la historia, acusando a Udaondo de extralimitarse en sus funciones, por haber "resuelto por su cuenta y riesgo" rendir un homenaje "que equivale a una consagración histórica" del General Uriburu. Partiendo de una marcada diferenciación entre la función de los museos - "guardar las reliquias del pasado para veneración, enseñanza y ejemplo de las generaciones presentes y futuras" - y la actividad histórica - "investigar, discutir o afirmar por su cuenta la categoría de los hechos sucedidos" -, criticaba el ambiguo rol del museo por asumir una tarea que en realidad le corresponde a la historiografía. "La historia la hace el pueblo y el tiempo la determina" - prosigue acusando a Udaondo de "faltar el respeto a la opinión nacional que todavía no ha pronunciado ni mucho menos su última palabra". Además, señalaba la imprudencia del accionar policial por disponer el envío a Luján de 150 hombres de la tropa de seguridad provincial "para que formen la guardia de honor en los actos sucesivos del homenaje resuelto". El periodista calificaba estos actos como de una

lamentable pérdida de la noción de medida. Porque aún suponiendo que el gobierno de la provincia de Buenos Aires estuviera facultado - cosa que estamos lejos de admitir- para introducir en la atmósfera serena y venerable del Museo de Luján, verdadero tabú de la historia y la tradición nacional, un espacio destinado a la duda, al odio, al rencor a la exaltación fervorosa y a la negación apasionada, que todo eso significaría la consagración de un hecho que aún no pertenece a la historia, sino a la actualidad viva y oscura, aún suponiendo eso decimos, tanto el señor director del Museo de Luján como el jefe de la policía provincial habrían olvidado en todo caso, en su precipitación, que el úkase del homenaje proyectado corresponde no a ellos sino a las cámaras legislativas y al Poder Ejecutivo de la Provincia. El director del Museo de Luján está evidentemente apurado por consagrar al Jefe de la Revolución de Septiembre ${ }^{50}$. 
50. EL FALLO de la historia, El Diario, Buenos Aires, 31 agosto 1932 .

\section{Ibidem.}

52. La Vanguardia, Buenos Aires, 4 sept. 1932

53. Véase Irina Podgorny (2007).
Concluía, advirtiendo que con su "obsesivo propósito" solo lograría que muchas familias se abstuvieran de hacer donaciones "visto que se está desvirtuando la naturaleza de ese claro hogar de la tradición nacional al introducir en él las pasiones y las discordias políticas cuyo eco aún no ha sido cubierto por el manto sereno y pacificador de la historia" ${ }^{\prime 51}$. El director del museo no contestó públicamente a las acusaciones; sin embargo recortó la nota periodística, la pegó en el libro dedicado a guardar la información relacionada con el museo y de puño y letra agregó debajo del fítulo "Se pidió autorización al P. E."; hizo un signo de interrogación donde se mencionaba que "el director del Museo, ha resuelto por su cuenta y riesgo" rendir homenaje y con flechas señaló la nota periodística aparecida en La Nación el 30 de agosto que transcribía el decreto oficial del Poder Ejecutivo que disponía los actos a realizarse con motivo del aniversario del 6 de septiembre.

Por otro lado, el diario socialista La Vanguardia coincidía con el cronista de El Diario aunque con mayor espíritu combativo. El mismo día de la inauguración advertía sobre la "obra oscura y reaccionaria" de Udaondo:

Se ha habilitado una sala del museo histórico para guardar los restos y menesteres de un
hombre que aún no se sabe cómo pasará a la historia. ¿Cómo puede justificarse una "sala
de Uriburu" en un museo cargado de reliquias de la historia nacional, destinado a recordar
hombres que realmente pertenecen a la historia?

Más allá de las implicancias políticas, estos aspectos merecen una reflexión cuidadosa teniendo en cuenta que se trataba de la propia concepción y definición de lo que debía ser un "museo histórico". Las acusaciones vertidas contra el director muestran que lo que se cuestionaba era la aceleración de los tiempos para "consagrar" un hecho que aún no formaba parte de la historia. Sin embargo si analizamos más detenidamente las prácticas y las estrategias diseñadas por Udaondo en los años previos para aumentar las salas, vemos que ello no era impensable.

En primer lugar, recordemos que el museo contaba con una sala dedicada al escritor Ricardo Güiraldes inaugurada a tan solo dos años de su muerte; y que en 1928 se había reconstruido el dormitorio de la hija de Bartolomé Mitre, Josefa Mitre de Caprile fallecida en 1925. Además, esta estrategia consistente en incorporar un espacio a las figuras consideradas dignas de recuerdo tampoco era exclusiva del Museo de Luján: en 1927 el director del Museo de la Plata, había inaugurado un espacio dedicado a recordar a Francisco P. Moreno - muerto en 1919 -, en un contexto políitico en el que se pretendía exaltar los valores del hombre consagrado como el creador e ideólogo del museo ${ }^{53}$. Pero ninguno de los tres casos referidos habían generado el menor debate respecto a la proximidad temporal con la que se honraba a los fallecidos. Es verdad que el caso de Uriburu superaba los ejemplos anteriores y que la propuesta se había gestado a escaso dos meses de su deceso, pero también debe mencionarse que la connotación política de la sala Güiraldes - como tampoco la de las salas dedicadas a las dos señoras de la elite - podían compararse con la del líder de la revolución de septiembre. 
En segundo lugar, recordemos que, a través de la circulación de noticias, folletos y catálogos, Udaondo conocía los museos de Argentina y del mundo y que ellos nutrieron sus concepciones sobre estrategias expositivas y montaje de exposiciones. Estos parámetros impulsaron el establecimiento de comparaciones, analogías y diferencias, y hacia 1930 determinaron los motivos por los cuales el Museo de Luján superaba la cantidad de visitantes que el propio director había imaginado: "Contribuye también a que sea tan frecuentado el hecho de que es muy variado dentro de su especialidad y están presentados los objetos de forma atrayente y moderna como se estila en los grandes museos del viejo mundo" 54 , mencionaba en las memorias oficiales de 1930.

Sumado a ello, en el Catálogo institucional publicado en 1934, alertaba a los críticos que creían

con criterio equivocado, que un Museo debe conservar solo objetos antiguos y critican que se exhiban coches de veinte o treinta años atrás: éstos vehículos tienen antecedentes históricos y el Museo debe recogerlos antes que desaparezcan arrumbados en un galpón o a la intemperie, como ha ocurrido con coches de importancia. Por otra parte, es sabido que los Museos europeos exhiben hasta automóviles sin ser históricos ${ }^{55}$

finalizaba, para defender su postura.

En efecto, con estas palabras Udaondo estaba explicitando su concepción de "museo": según su criterio, un institución de este tipo "orientada por los criterios modernos" aceptados internacionalmente, no necesariamente estaba dedicado a exponer "objetos antiguos"; de ahí el motivo por el cual al interior de salas el visitante se topara con todo tipo de piezas que incluían desde cuadros y pinturas de reciente producción hasta reconstrucciones de escenas montadas con muñecos, animales embalsamados y diversos materiales de uso cotidiano.

Finalmente, recordemos que el Museo Histórico Nacional instalado en la ciudad de Buenos Aires contenía ya algunos muebles del dormitorio de San Martín donados por su nieta y trasladados desde Boulogne Sur Mer a fines del siglo XIX, cuando Adolfo P. Carranza dirigía el museo: ${ }^{56}$ la reconstrucción del dormitorio del "Gran Capitán" fue inaugurada oficialmente como espacio museográfico mucho después del de Luján, el 17 de agosto de 1935, por impulso de Federico Santa Coloma Brandsen quien asumió la dirección del museo en 1932 por propuesta del presidente Justo. Pero desde 1899 los muebles habían permanecido resguardados en el Museo Histórico aunque su disposición al interior de las salas no respondía al plano enviado por la donante con el objetivo de reconstruir el ámbito del dormitorio del prócer. Aún resta mucho por explorar respecto a la formación de las colecciones y las estrategias expositivas del Museo Histórico Nacional, pero no es arriesgado pensar que hacia 1932 Udaondo conociera estos planos y documentos institucionales y que por lo tanto, salvando las distancias, los tuviera en mente a la hora de diseñar la sala Uriburu.

Excluyendo entonces las reivindicaciones políticas que sin duda eran evidentes en la nueva sala, Udaondo actuaba acorde a algunos lineamientos y normas aceptadas internacionalmente en materia de museos. Si se generaba el debate era porque más allá de las propuestas museográficas, tanto impulsores
54. Véase Museo Histórico y Colonial de la Provincia de Buenos Aires (1930), BORRADOR manuscrito de la memoria de 1930, Archivo del Complejo Museografico Enrique Udaondo; destacado nuestro.

55. Véase Sánchez Zinny (1934, p. 113); destacado en el original.

56. Cf. Ernesto Quesada (1901, p. 49ss.); Sobre la inauguración de nuevas salas, véase Ricardo Levene y Federico Santa Coloma Brandsen (1935). 
57. Cf. Ulpiano Bezerra de Meneses $(1994 ; 2003)$.

58. Respecto a los historiadores nucleados en este grupo, cf. Fernando Devoto y Nora Pagano (2009, p. 139-200). como detractores de la propuesta lo consideraban un "hecho político". Y en efecto, en la Argentina de 1932, cuando los seguidores de Uriburu comenzaban a perder poder, lo era. Pero su materialización estaba asentada en una serie de prácticas previas en materia de diseño y concepción de museo que lo hacían posible: desde 1923 Udaondo había ido modelando un tipo de museo reconocido públicamente como "histórico" donde en efecto era posible que a través de la dimensión visual, acontecimientos del pasado inmediato pasaran a ser "evocados" como parte de la historia ${ }^{57}$. Quizás entonces, el concepto de "museo moderno" al que Udaondo refiere una y otra vez en la propaganda institucional, esté dado más por esa ruptura innovadora y radical sobre la concepción de la práctica historiográfica - entendida esta como el estudio científico y pormenorizado de las producciones escritas del pasado - que sobre la utilización de las técnicas expositivas: en síntesis, el montar la sala Uriburu reflejaba que para Udaondo, reconocido por sus pares como miembro de la corporación de historiadores, la práctica de la historia comenzaba a quedar cada vez más lejana del "museo moderno". Y aunque puertas adentro de la institución reproducía sus experiencias previas como historiador, el museo que dirigía estaba lejos de ser un centro de investigación y producción historiográfica tal cual lo entendían los historiadores de la Nueva Escuela Histórica ${ }^{58}$ para transformarse en un espacio de "evocación" y exposición de "objetos fabricados" para un público cada vez mas amplio, que hacia 1932 debía ser "instruido visualmente" con un claro objetivo político.

\section{Conclusión}

Luego del 6 de septiembre de 1930 Udaondo fortaleció sus relaciones formales e informales con funcionarios públicos, políticos y agrupaciones nacionalistas, del ejército y de la iglesia católica. Fallecido Uriburu y en un contexto de reacomodamiento de las alianzas políticas, el montaje de la sala - impulsada por un allegado del reciente fallecido - fue retomada por el director del museo como estrategia para generar nuevos apoyos a nivel gubernamental y dar cuenta de la vigencia del movimiento nacionalista.

A la iniciativa se plegaron familiares, amigos, funcionario públicos, miembros de la elite y del Ejército - que detentaban cargos políticos y manejaban los resortes del Estado - para modelar un relato histórico heroico sobre acontecimientos recientes con una clara intencionalidad política. Como vimos, muchas de las piezas entregadas en donación eran objetos personales y fotografías, pinturas, cartas y autógrafos producidos recientemente que adoptaban el carácter de "reliquia histórica" al ser expuesta: en realidad se trataba de objetos que los donantes aseveraban, habían tenido relación con Uriburu o con acontecimientos político desarrollado durante su gobierno.

Sin embargo, la propuesta se materializó también a través de la participación de una nutrida red de proveedores, coleccionistas, artistas y comerciantes menos interesados en el nacionalismo que en obtener beneficios derivados de sus 
nuevas posibilidades laborales. En este contexto, el montaje de un nuevo espacio significaba la puesta en movimiento de un complejo dispositivo de trabajos colectivos que reportaban beneficios económicos concretos y contribuían al mismo tiempo a la fabricación comercial de evidencias.

Por otro lado, las estrategias expositivas basadas en la reconstrucción de escenas, los muñecos de cera, fotoesculturas y reproducciones de Uriburu dan cuenta de la utilidad de los mecanismos expositivos de vanguardia que circulaban a nivel mundial para captar la atención de un público cada vez más masivo, paradójicamente como medio para exaltar a una figura vinculada al más acérrimo nacionalismo.

La aceptación del desafío generó una involuntaria puesta en discusión respecto a que se entendía por "museo" y cuales eran sus funcionalidades ya que no se limitaba a la recolección y exposición de "objetos antiguos". Este debate, generado ante un episodio concreto, no estaba desvinculado de las discusiones internacionales respecto a la definición de instituciones de ésta índole y fue precisamente Udaondo el que se percató de ello explicitando en la Argentina los alcances y funcionalidades del "concepto moderno de museo". Sin embargo, esta concepción (que comenzó a explicitarse en 1932) "rompió el molde" respecto a la relación entablada entre la práctica de la historia y la exhibición museográfica: en este sentido, la decisión de inaugurar una sala sobre un hecho político acaecido recientemente, marcaba el quiebre de aquel supuesto enunciado en el reglamento del museo de 1924 que lo presentaba como "un instituto técnico y docente" cuyo objeto era "reunir, conservar, custodiar y exhibir reliquias, objetos, documentos del pasado argentino, especialmente de la época colonial"59. Es verdad que la palabra "especialmente" advertía sobre la posibilidad de incluir también otras; sin embargo se hablaba del "pasado argentino" y nada decía sobre el pasado reciente ni sobre los "hechos políticos". Tuvieron que pasar más de cincuenta años para que el tema fuera nuevamente puesto en discusión y se tomara una nueva determinación sobre "que hacer" con la Sala Uriburu que permaneció instalada en el museo hasta el advenimiento de la democracia, en 1983: en ese año y con las secuelas visibles de la última dictadura militar que sufrió la Argentina entre 1976 y 1983, se consideró adecuado reemplazarla por una exposición de "muebles chinos" que si bien no tenían afinidad con la "época colonial" tampoco exaltaba el recuerdo del primer golpe militar de la historia argentina.

Pero creemos que el desafío actual es otro y radica fundamentalmente en poder analizar de manera académica, discutir y hacer llegar a un público mucho más amplio, la multiplicidad de causas y de criterios - políticos, historiográficos, ideológicos o de otro tipo - por los cuales los promotores, directores y colaboradores de los museos seleccionaron (y continúan seleccionando) los materiales y los espacios de exhibición de los institutos denominados "históricos". 


\section{REFERÊNCIAS}

\section{FONTES MANUSCRITAS O MECANOGRAFIADAS}

Fondo Udaondo de la Academia Nacional de la Historia (caja 47)

CARTA de Rafael D. del Villar a Udaondo, 31 marzo 1931, f. 140.

BORRADORES de la memoria del año 1930, f. 148-153

BORRADORES de la programación del acto, caja 47, f. 226-229.

NOTIFICACIÓN oficial del Ministerio, 2 enero 1931,f. 143.

ARCHIVO DEL COMPLEJO MUSEOGRÁFICO ENRIQUE UDAONDO:

ACTAS de donaciones Sala Uriburu,f. 4 B; f. 53 M,f. 16, 65-67, 71 MG;f. 17-25 C;f. 26 C.f. 52 C; f. 4

B, 137, 68-70 MG. f. 13 C, 14, 14 bis y 15;f. 18, 20, 21, 22, 27, 30, 63 MG;f. 72 MG, 51 E;

BORRADOR manuscrito de la memoria de 1930.

CARTAS de agradecimiento de Uriburu a su "Estimado amigo Udaondo", 28 oct. 1932; 15 dic. 1932, Actas de donaciones de la Sala Uriburu, correspondencia.

CARTA de agradecimiento de Udaondo a Uriburu, 1. oct. 1931, Livro Copiador: cartas y notas de Udaondo (octubre 1929-abril 1933), f. 525.

PAPELES Sala Uriburu, f. 5-8; f. 26; f. 29; f. 34-35.

REGLAMENTO del Museo Histórico y Colonial de la Provincia de Buenos Aires, Manuscrito. 1924.

\section{LIBROS Y REVISTAS}

BÉJAR, Maria Dolores. El régimen fraudulento. La política en la provincia de Buenos Aires, 19301943. Buenos Aires: Siglo XXI, 2005.

BEZERRA DE MENESES, Ulpiano. Fontes visuais, cultura visual, história visual. Balanço provisório, propostas cautelares. Revista Brasileira de História, São Paulo, v. 23, n. 45, p. 11-36, 2003.

Do teatro da memória ao laboratório da história: a exposição museológica e o conhecimento histórico. Anais do Museu Paulista: História e Cultura Material, São Paulo, v. 2, p. 9-42, 1994.

BISSO,Andrés. El gobernador Fresco y las conmemoraciones del aniversario del Golpe de Estado del 6 de septiembre de 1930. In: REITANO, Emir (Org.). El gobierno de Manuel Fresco en la provincia de Buenos Aires (1936-1940). La Plata:Archivo Histórico de la Provincia de Buenos Aires, 2010 (en prensa).

CATTARUZZA,Alejandro. Descifrando pasados: debates y representaciones de la historia nacional. In:___ (Org.). Nueva Historia Argentina. Crisis económica, avance del Estado e incertidumbre política (1930-1943). Buenos Aires: Sudamericana, 2001. p. 429-476. 
El revisionismo: itinerarios de cuatro décadas. In:

; EUJANIAN Alejandro. Políticas de la Historia Argentina (1860-1960). Buenos Aires:Alianza, 2003. p. 143-182.

DEVOTO, Fernando. Nacionalismo, fascismo y tradicionalismo en la Argentina moderna. Buenos Aires: Siglo XXI, 2002

; PAGANO, Nora. Historia de la bistoriografía argentina. Buenos Aires: Sudamericana, 2009. p. 201-285.

FINCHELSTEIN, Federico. Fascismo, liturgia e imaginario. El mito del general Uriburu y la Argentina nacionalista. Buenos Aires: Fondo de Cultura Económica, 2002.

HALPERIN DONGHI,Tulio. Vida y muerte de la república verdadera (1910-1930). Buenos Aires: Ariel, 1999.

La Argentina y la tormenta del mundo. Buenos Aires: Siglo XXI, 2003.

La República imposible, 1930-1945. Buenos Aires:Ariel, 2004.

LEVENE, Ricardo; SANTA COLOMA BRANDSEN, Federico. Homenaje al Libertador José de San Martín. Conferencia de Ricardo Levene sobre "San Martín, síntesis de la historia argentina" y Federico Santa Coloma Brandsen sobre "El Museo Histórico Nacional e inauguración de las nuevas salas". Buenos Aires: Museo Histórico Nacional, 1935.

LOPES, Maria Margaret; PODGORNY, Irina. El desierto en una vitrina. Museos e historia natural. México: Limusa, 2008.

McGEE DEUTSCH, Sandra. Contrarrevolución en la Argentina 1900-1932. La Liga Patriótica Argentina. Buenos Aires: Universidad Nacional de Quilmes, 2003.

PODGORNY, Irina. El argentino despertar de las faunas y de las gentes prehistóricas. Coleccionistas, museos y estudiosos en la Argentina entre 1880 y 1910. Buenos Aires: Eudeba; Libros del Rojas, 2000.

La mirada que pasa: museos, educación pública y visualización de la evidencia científica. História, Ciências, Saúde-Manguinbos, Rio de Janeiro, v. 12, p. 231-264, 2005.

Embodied Institutions. La Plata Museum as Francisco P. Moreno's Autobiography. In:VALENTE, Maria Esther Alvarez (Org.). Museums of Science and Technology. Interpretations and Activities to the Public. Rio de Janeiro: Museu de Astronomia e Ciências Afins; Cimuset, 2007. p. 95-103.

QUATTROCCHI-WOISSON, Diana. Los males de la memoria. Historia y política en la Argentina. Buenos Aires: Emecé, 1995.

QUESADA, Ernesto. Las reliquias de San Martín. Estudio de las colecciones del Museo Histórico Nacional (1899). 3. ed. Buenos Aires: Imprenta Europea de M.A. Rosas, 1901.

ROMERO, Luis Alberto. Breve historia contemporánea de Argentina. Buenos Aires: Fondo de Cultura Económica, 1994.

Una nación católica: 1880-1946. In:ALTAMIRANO, Carlos (Org.). La Argentina en el siglo XX. Buenos Aires:Ariel, 1999. p. 314-324.

La crisis argentina. Una mirada al siglo XX. Buenos Aires: Siglo XXI, 2003.

SÁNCHEZ ZINNY, D. E. F. Catálogo del Museo Colonial e Histórico de Luján. Luján: El Arte, 1934.

Annals of Museu Paulista. v. 19. n.1. Jan.-June 2011. 
ZANATTA, Loris. Del Estado liberal a la nación católica. Iglesia y ejército en los orígenes del peronismo. Buenos Aires: Universidad Nacional de Quilmes, 1996.

\section{PERIODICOS DIARIOS}

Crítica, Buenos Aires, 19 de sept. 1930.

Crítica, Buenos Aires, 29 de sept. 1930.

El Diario, Buenos Aires, 19 de sept. 1930.

El Diario, Buenos Aires, 29 de sept. 1930.

El Mundo, Buenos Aires, 19 de sept. 1930.

El Mundo, Buenos Aires, 29 de sept. 1930.

El Oeste, Buenos Aires, oct. 1932.

El Progreso, Luján, 6 de sept. 1930.

El Progreso, Luján, 27 de sept. 1930.

El Pueblo, Buenos Aires, 9 sept. 1930.

El Pueblo, Buenos Aires, 29 sept. 1930.

La Fronda, Buenos Aires, 5 sept. 1932.

La Nación, Buenos Aires, 18 sept. 1930.

La Razón, Buenos Aires, 4 sept. 1932.

Nativa, Buenos Aires, 1 oct. 1930.

Artigo apresentado em 10/2010. Aprovado em 3/201 1. 